\title{
Environmental monitoring results from the third periodic evaluation of progress towards the objective of the OSPAR radioactive substances strategy*
}

\author{
J.P. GWYNN ${ }^{1}$
}

(Manuscript received 5 July 2010, accepted 12 July 2010)

ABSTRACT The general objective of the OSPAR radioactive substances strategy is to prevent pollution of the maritime area from ionising radiation through progressive and substantial reductions of discharges, emissions and losses of radioactive substances, so that concentrations in the environment are close to background for naturally occurring radioactive substances and close to zero for artificial radioactive substances. The third periodic evaluation of progress towards the objective of the OSPAR radioactive substances strategy concludes that, due to issues concerning the availability of reported data, it is not possible to come to firm conclusions as to whether the aims of the OSPAR radioactive substances strategy are currently being delivered. However, in general there is an indication of a reduction in average marine concentrations of selected radionuclides associated with the nuclear industry, while doses arising from these selected radionuclides in the OSPAR maritime area to humans are well within internationally recommended limits and are below the lowest levels at which any effects are likely to occur for marine biota.

Keywords: Radioactive substances strategy / maritime area / ionising radiation

RÉSUMÉ Résultats de la surveillance de l'environnement - Troisième évaluation périodique de la progression dans le sens de la réalisation de l'objectif de la stratégie substances radioactives d'OSPAR.

L'objectif général de la stratégie de substances radioactives d'OSPAR est d'empêcher la pollution de la zone maritime par des rayonnements ionisants par des réductions progressives et substantielles de rejets, d'émissions et de pertes de substances radioactives, de sorte que les concentrations dans l'environnement soient proches du bruit de fond des substances radioactives naturelles et de zéro pour les substances radioactives artificielles. La troisième évaluation périodique de l'avancement vers l'objectif de la stratégie de substances radioactives d'OSPAR conclut que, en raison des questions sur la disponibilité des données enregistrées, il n'est pas possible de savoir si les objectifs d'OSPAR sont actuellement atteints. Cependant, on note, en general, une indication de réduction des concentrations marines moyennes des radionucléides choisis pour l'industrie nucléaire, alors que les doses à l'homme résultant de ces radionucléides, dans la zone maritime d'OSPAR sont tout à fait en conformité avec des limites internationalement recommandées et sont au-dessous des niveaux les plus bas auxquels tous les effets sont susceptibles d'apparaitre pour le biota marin.

\footnotetext{
* Article already published in French in Contrôle, No. 188, pp. 143-148 (July 2010), reprinted with permission from ASN publications.

1 Norwegian Radiation Protection Authority, Troms $\varnothing$, Norway.
} 
The OSPAR convention is the current legal instrument guiding international cooperation on the protection of the marine environment of the North-East Atlantic. Work under the convention is managed by the OSPAR commission, made up of representatives of the Governments of 15 contracting parties (Belgium, Denmark, Finland, France, Germany, Iceland, Ireland, Luxembourg, The Netherlands, Norway, Portugal, Spain, Sweden, Switzerland and the United Kingdom) and the European Commission, representing the European Community.

The mission of the OSPAR convention is to conserve marine ecosystems and safeguard human health in the North-East Atlantic by preventing and eliminating pollution; by protecting the marine environment from the adverse effects of human activities; and by contributing to the sustainable use of the seas.

The OSPAR commission works under the umbrella of customary international law as codified by the 1982 United Nations convention on the Law of the Seas. The OSPAR convention recognises the jurisdictional rights of states over the seas and the freedom of the High Seas, and, within this framework, the application of the main principles of international environmental policy to prevent and eliminate marine pollution and to achieve sustainable management of the maritime area.

Overall, the work of the OSPAR commission is guided by the ecosystem approach to an integrated management of human activities in the marine environment. This is supported by a general obligation of contracting parties to apply

- the precautionary principle;

- the polluter pays principle;

- best available techniques (BAT) and best environmental practice (BEP), including clean technology.

OSPAR has developed, and is implementing, a suite of five thematic strategies to address the main threats that it has identified within its competence (the biodiversity and ecosystem strategy, the eutrophication strategy, the hazardous substances strategy, the offshore industry strategy, and the radioactive substances strategy), together with a strategy for the joint assessment and monitoring programme, which assesses the status of the marine environment and follows up implementation of the strategies and the resulting benefits to the marine environment. These six strategies fit together to underpin the ecosystem approach.

\section{OSPAR radioactive substances strategy}

The OSPAR radioactive substances strategy provides that: "In accordance with the general objective [of the OSPAR convention], the objective of the commission 
with regard to radioactive substances, including waste, is to prevent pollution of the maritime area from ionising radiation through progressive and substantial reductions of discharges, emissions and losses of radioactive substances, with the ultimate aim of concentrations in the environment near background values for naturally occurring radioactive substances and close to zero for artificial radioactive substances. In achieving this objective, the following issues should, inter alia, be taken into account:

a. legitimate uses of the sea,

b. technical feasibility,

c. radiological impacts on man and biota."

The strategy further provides that: "this strategy will be implemented in accordance with the programme for more detailed implementation of the strategy with regard to radioactive substances (the "RSS implementation programme"). In order to achieve [its objective] by the year 2020, the commission will ensure that discharges, emissions and losses of radioactive substances are reduced to levels where the additional concentrations in the marine environment above historic levels, resulting from such discharges, emissions and losses, are close to zero."

\section{Evaluation methodology and limitations of approach adopted}

In order to demonstrate progress towards fulfilling the objectives of the strategy, the OSPAR commission is called upon to periodically evaluate progress against an agreed baseline. For the OSPAR radioactive substances strategy, a baseline period corresponding to the period from 1995 to 2001 has been agreed upon for the evaluation of both discharges and environmental concentrations of radioactive substances in the OSPAR maritime area.

In 2009 and as part of the third periodic evaluation ${ }^{2}$ of progress towards the objective of the radioactive substances strategy (OSPAR, 2009), OSPAR assessed environmental concentrations of selected radionuclides $\left({ }^{3} \mathrm{H},{ }^{99} \mathrm{Tc},{ }^{137} \mathrm{Cs}\right.$ and ${ }^{239}, 240 \mathrm{Pu}$ ) associated with the nuclear industry in the OSPAR maritime area, by comparing average levels in seawater and marine biota (seaweed, molluscs and fish) during an assessment period of 2002 to 2006 with corresponding values from the agreed baseline period. OSPAR contracting parties had previously agreed upon a monitoring agreement whereby data on concentrations of ${ }^{3} \mathrm{H},{ }^{99} \mathrm{Tc},{ }^{137} \mathrm{Cs}$ and ${ }^{239,240} \mathrm{Pu}$ in the marine environment would be reported to OSPAR where available through existing national marine monitoring programmes. For this purpose, the OSPAR maritime area was subdivided into 15 monitoring areas, generally

\footnotetext{
2 The Third Periodic Evaluation of progress towards the objective of the OSPAR Radioactive Substances Strategy is available from the OSPAR website www.ospar.org.
} 
representing subdivisions of the five wider designated regions of the OSPAR maritime area and taking into account prevailing currents. (Fig. 1). Annual means have been determined on the basis of all data reported (i.e. in some cases from data from more than one contracting party) for each individual radionuclide in a particular compartment (i.e. seawater or biota) for a particular region. The available concentration data reported to OSPAR have allowed baseline values for the period 1995 to 2001 to be determined for some of the selected radionuclides, both in seawater and in biota, but baseline values could not be derived for all monitoring regions, selected radionuclides and selected biota.

OSPAR has developed a two-step methodology for evaluating progress towards the objective of the radioactive substances strategy. Firstly, a simple comparison is performed to determine whether the mean of the assessment period lies outside the $95 \%$ confidence limits of the corresponding mean value for the baseline period. This is then followed by the use of more sophisticated parametric and nonparametric statistical tests to determine whether any change between the assessment period and the baseline period is statistically significant. When both the parametric and non-parametric statistical tests agree that the basic hypothesis can be rejected and that there has been a change in data since the baseline period, this is deemed to be 'statistically significant'. Where the tests disagree, and only one test indicates that there has been a change since the baseline period, this indicates that there is 'some evidence' of an increase or reduction since the baseline period.

At present, caution must be exercised when interpreting the results of the evaluation process, due in some cases to the limited number of data points available in particular datasets; where differences may exist in sampling and analytical methodologies between contracting parties; or where there exist a relatively high number of data values below the limits of detection in some datasets. In the instance of data values below the limits of detection, OSPAR has developed appropriate methodologies to incorporate such data into the evaluation process, but in datasets where the number of values below the limits of detection was more than $80 \%$ of the total dataset, it has not been possible to carry out any statistical assessments. Longer time series of the existing datasets may allow more accurate and comprehensive conclusions to be reached in future.

In addition, it should be noted that it is difficult to draw direct comparisons between evaluations of discharges and environmental concentrations as:

- the transport of radionuclides by sea currents may involve a time lag between their discharge and their measurement as environmental concentrations. This will differ between OSPAR regions and could, for example, amount to several years. Furthermore, chemical reactions in the marine environment could affect concentration data; 


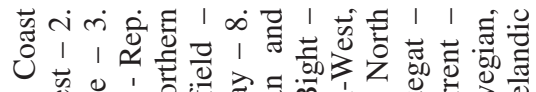

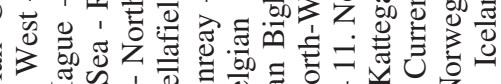

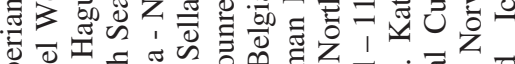

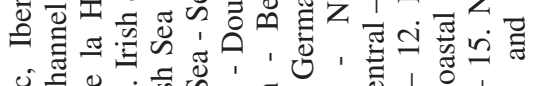

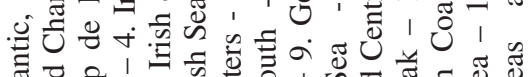

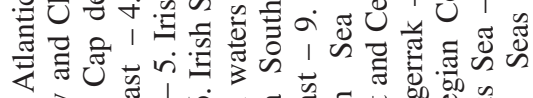

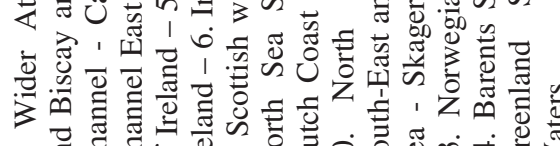

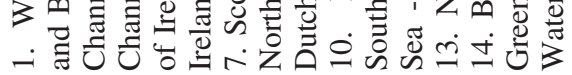
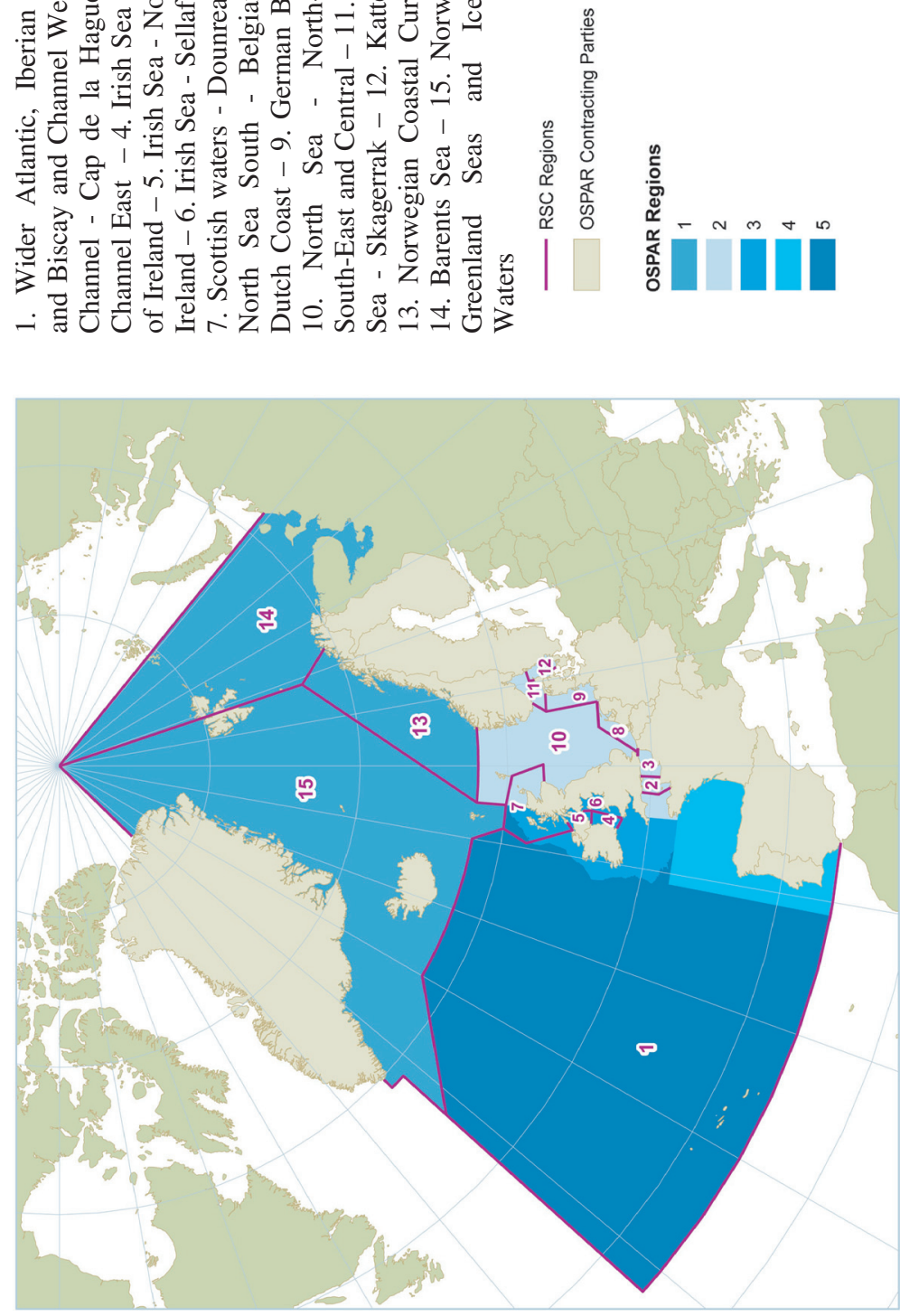
- concentrations may also be influenced by other sources of the selected radionuclides, i.e. global nuclear fall-out from atmospheric weapons tests, the Chernobyl accident, etc.

- some of the measured concentrations may be influenced by the remobilisation of radionuclides in sediments from discharges made in the past.

\section{General conclusions for marine concentrations}

Where seawater concentration data have been reported (41 separate datasets established), data values are predominantly derived from coastal sampling stations, supplemented in some cases by data from open ocean stations. For ${ }^{137} \mathrm{Cs}$ in seawater, datasets are available for all 15 monitoring regions, whereas for ${ }^{3} \mathrm{H}$, ${ }^{99} \mathrm{Tc}$ and ${ }^{239,240} \mathrm{Pu}$, datasets are available for only 9, 10 and 7 monitoring regions, respectively. The highest baseline value $(0.18 \mathrm{~Bq} / \mathrm{l})$ and mean value for the assessment period $(0.10 \mathrm{~Bq} / \mathrm{l})$ for ${ }^{137} \mathrm{Cs}$ in seawater were observed in monitoring region 6 (Irish Sea - Sellafield), as was the case for ${ }^{99} \mathrm{Tc}(0.36 \mathrm{~Bq} / \mathrm{l}$ baseline value; $0.14 \mathrm{~Bq} / \mathrm{l}$ mean value for the assessment period).

Where marine biota concentration data have been reported (40 separate datasets established), data generally relate to coastal measurements with the exception of certain monitoring results in fish. Only data for ${ }^{99} \mathrm{Tc},{ }^{137} \mathrm{Cs}$ and ${ }^{239,240} \mathrm{Pu}$ are reported for marine biota as there is generally little bioaccumulation of ${ }^{3} \mathrm{H}$ by marine biota (with the exception of compounds containing organically bound tritium). For ${ }^{137} \mathrm{Cs}$ in marine biota (mainly for seaweed or fish), 18 datasets are available from all 15 monitoring regions. For ${ }^{99} \mathrm{Tc}$, datasets for concentrations in seaweed are available for 12 monitoring regions, while for ${ }^{239,240} \mathrm{Pu}, 10$ datasets (for molluscs or fish) are available for 9 monitoring regions. Where datasets are available for ${ }^{137} \mathrm{Cs}$ in fish ( 8 monitoring regions), the highest baseline value (2.95 Bq/kg f.w.) and mean value for the assessment period (5.83 Bq/kg f.w.) were observed in monitoring region 12 (Kattegat). Only data for ${ }^{137} \mathrm{Cs}$ in molluscs are available from monitoring region 6 (Irish Sea - Sellafield). The highest baseline value $(9260 \mathrm{~Bq} / \mathrm{kg}$ f.w.) and mean value for the assessment period $(3730 \mathrm{~Bq} / \mathrm{kg}$ f.w.) for ${ }^{99} \mathrm{Tc}$ in seaweed were observed in monitoring region 6 (Irish Sea Sellafield), at least an order of magnitude higher than any other monitoring region.

For reported seawater concentration data, statistical evaluations were possible in 27 out of the 41 datasets. Of these 27 datasets, there has been a statistically significant change in 6 instances, with each of these 6 instances indicating a decrease in the concentration of one of the selected radionuclides in seawater in the assessment period as compared with the baseline period. For a further 7 datasets there is some evidence indicating change, with 4 instances indicating a decrease and 3 instances indicating an increase in the concentration of one of the selected 
radionuclides in seawater in the assessment period as compared with the baseline period. Of the remaining 14 datasets where statistical evaluations were possible, no statistically significant change was observed in the concentrations of the selected radionuclides in seawater between the assessment period and the baseline period.

For concentrations in marine biota, statistical evaluations were possible in 34 out of the 40 datasets. Of these 34 datasets, there has been a statistically significant change in 18 instances, with 17 of these instances indicating a decrease in the concentration of one of the selected radionuclides in marine biota in the assessment period as compared with the baseline period. In the remaining instance where there had been a statistically significant change $\left({ }^{137} \mathrm{Cs}\right.$ in fish in monitoring region 12 (Kattegat)), an increase in concentrations in the assessment period as compared with the baseline period was indicated. For a further 4 datasets, there is some evidence indicating change, with 2 instances indicating a decrease and 2 instances indicating an increase in the concentration of one of the selected radionuclides in marine biota in the assessment period as compared with the baseline period. Of the remaining 12 datasets where statistical evaluations were possible, no statistically significant change was observed in the concentrations of the selected radionuclides in marine biota between the assessment period and the baseline period.

The reporting of marine environmental concentrations of naturally occurring radionuclides associated with discharges from non-nuclear industries, and in particular with discharges of produced water from the offshore oil and gas sector, is not included under the existing monitoring agreement (currently under review) and as a result, no assessment can be made of the limited data available for these radionuclides. Where such data have been reported it is important to note that these data represent total environmental concentrations, i.e. they reflect natural background concentrations and possible contributions from discharges of these radionuclides from non-nuclear industries and as the concentration of these radionuclides from natural sources can vary quite considerably, it may be difficult to detect elevated levels originating from non-natural sources.

\section{Doses to members of the public from the consumption of seafood}

Doses to members of the public from the consumption of seafood have been estimated using two different approaches derived from the MARINA II model (MARINA II, 2003):

1. doses derived from reported concentrations in seawater - doses to humans were determined based on the consumption of fish, molluscs and crustaceans, 
with concentrations of the selected radionuclides in these 3 types of marine biota simulated from reported concentrations in seawater;

2. doses derived from reported concentrations in marine biota - doses to humans were determined from the individual consumption of fish or molluscs and the actual reported concentrations of the selected radionuclides for these marine biota.

In both cases, doses to members of the public were derived for concentration baseline values and mean concentration values for the assessment period and only for datasets where all data values are above detection limits.

All doses determined for humans arising from the selected radionuclides associated with the nuclear industry in the OSPAR maritime area are well within (and in the large majority of cases, a small fraction of) the limits recommended by the International commission on radiological protection (ICRP) and, where appropriate, comply with the basic safety standards for those OSPAR contracting parties within the European Union.

Doses to humans derived from concentrations of the selected radionuclides associated with the nuclear industry in seawater cover a wide range of values across the various monitoring regions, with doses of the order of $10^{-3} \mu \mathrm{Sv} / \mathrm{yr}$ for ${ }^{3} \mathrm{H}, 10^{-3}$ to $10^{0} \mu \mathrm{Sv} / \mathrm{yr}$ for ${ }^{99} \mathrm{Tc}, 10^{-1}$ to $10^{0} \mu \mathrm{Sv} / \mathrm{yr}$ for ${ }^{137} \mathrm{Cs}$ and $10^{-2}$ to $10^{-1} \mu \mathrm{Sv} / \mathrm{yr}$ for ${ }^{239,240} \mathrm{Pu}$. In line with patterns for concentration data, doses arising from ${ }^{99} \mathrm{Tc}$ and ${ }^{137} \mathrm{Cs}$ in seawater decline with distance from the highest value in monitoring region 6 (Irish Sea - Sellafield).

In comparison and from the limited data available for concentrations of naturally occurring radionuclides reported in seawater over the period 1995 to 2006, doses to humans based on annual means were of the order of $10^{0}$ to $10^{2} \mu \mathrm{Sv} / \mathrm{yr}$ for ${ }^{226} \mathrm{Ra}$ and $10^{-1}$ to $10^{1} \mu \mathrm{Sv} / \mathrm{yr}$ for ${ }^{228} \mathrm{Ra}$. These doses are up to 2 orders of magnitude higher than the highest dose to humans arising from concentrations of the selected radionuclides associated with the nuclear industry in seawater.

Doses to humans derived directly from concentrations of the selected radionuclides associated with the nuclear industry occurring in seafood also cover a wide range of values across the various monitoring regions, with doses of the order of $10^{-2}$ to $10^{0} \mu \mathrm{Sv} / \mathrm{yr}$ for ${ }^{137} \mathrm{Cs}$ (molluscs and fish) and $10^{-2}$ to $10^{1} \mu \mathrm{Sv} / \mathrm{yr}$ for ${ }^{239,240} \mathrm{Pu}$ (molluscs). The highest dose to humans from ${ }^{239,240} \mathrm{Pu}$ in seafood occurs in monitoring region 6 (Irish sea - Sellafield), while doses arising from ${ }^{239,240} \mathrm{Pu}$ in seafood in other monitoring regions are at least 2 orders of magnitude lower. Concentrations of ${ }^{99} \mathrm{Tc}$ have only been reported in seaweed, which is not a significant dietary exposure pathway to humans and was therefore not included in the dose assessment. 
In comparison and from the limited data available for concentrations of naturally occurring radionuclides reported in marine biota over the period 1995 to 2006 , doses to humans based on annual means were of the order of $10^{-2}$ to $10^{-1} \mu \mathrm{Sv} / \mathrm{yr}$ for ${ }^{226} \mathrm{Ra}$ (molluscs), $10^{-1}$ to $10^{1} \mu \mathrm{Sv} / \mathrm{yr}$ for ${ }^{210} \mathrm{~Pb}$ (molluscs and fish) and $10^{1}$ to $10^{2} \mu \mathrm{Sv} / \mathrm{yr}$ for ${ }^{210} \mathrm{Po}$ (molluscs and fish). These doses are up to 1 order of magnitude higher than the highest dose arising from the selected radionuclides associated with the nuclear industry.

\section{Doses to marine biota}

An impact assessment of environmental concentrations of the selected radionuclides associated with the nuclear industry on marine biota has been carried out using the environmental risk assessment (ERA) methodology proposed by the European project ERICA (ERICA, 2007), the only European reference project that allows a fully integrated assessment of doses to biota. Total absorbed radiological dose rates have been assessed by comparison with the screening dose rate recommended by ERICA. This value, $10 \mu \mathrm{Gy} / \mathrm{h}$ for a generic ecosystem, has been selected as it is highly conservative and the lowest of any recommended screening values.

Total absorbed radiological dose rates for 3 representative classes of marine biota (seaweed, crab and fish) were derived from summing the individual dose rates derived for each individual selected radionuclide from reported concentrations in seawater where data were available for each monitoring region. In each instance, all data available in the datasets (i.e. data above and below detection limits) were used in the assessment.

For each year, the maximum total dose rate estimated for either seaweed, crab or fish for all monitoring regions based on reported concentrations of the selected radionuclides associated with the nuclear industry in seawater was less than $10 \%$ of the $10 \mu \mathrm{Gy} / \mathrm{h}$ screening level, with maximum total dose rates in all monitoring regions except monitoring region 6 (Irish sea - Sellafield) below 1\% of the $10 \mu \mathrm{Gy} / \mathrm{h}$ screening level. On this basis, the calculated dose rates to marine biota from the selected radionuclides associated with the nuclear industry are low and are below the lowest levels at which any effects are likely to occur according to current scientific understanding.

\section{Overall conclusions}

Due to issues concerning the availability of reported data, in particular for the nuclides discharged by non-nuclear industries, it is not possible to come to firm conclusions as to whether the aims of the OSPAR radioactive substances strategy 
are currently being delivered. However, in general there is an indication of a reduction in average marine concentrations of the selected radionuclides associated with the nuclear industry; as where statistical tests indicated a statistically significant difference between the baseline period and the assessment period, the change indicated a decrease in every case but one. However, some OSPAR regions are still experiencing elevated concentrations due to outflowing Baltic water that has been contaminated with fallout from the Chernobyl accident or due to remobilisation of radionuclides from Irish Sea sediments as a result of past discharges.

All doses determined for humans arising from the selected radionuclides associated with the nuclear industry in the OSPAR maritime area are well within internationally recommended limits.

Calculated total doses to marine biota arising from the selected radionuclides associated with the nuclear industry are below the lowest levels at which any effects are likely to occur.

\section{REFERENCES}

ERICA (2007) D-ERICA: An integrated approach to the assessment and management of environmental risk from ionising radiation, Final Deliverable, European Commission, 6th Framework, N. Beresford, J. Brown, D. Copplestone, J. Garnier-Laplace, B. Howard, C.M. Larsson, D. Oughton, G. Pröhl, I. Zinger (Eds). Contract No. FI6R-CT-2003-508847.

MARINA II (2003) European Commission, Update of the MARINA Project on the radiological exposure of the European Community from radioactivity in North European marine waters.

OSPAR (2009) Third Periodic Evaluation of Progress towards the Objective of the Radioactive Substances Strategy. OSPAR Commission, London, 2009. Publication 455/2009. 